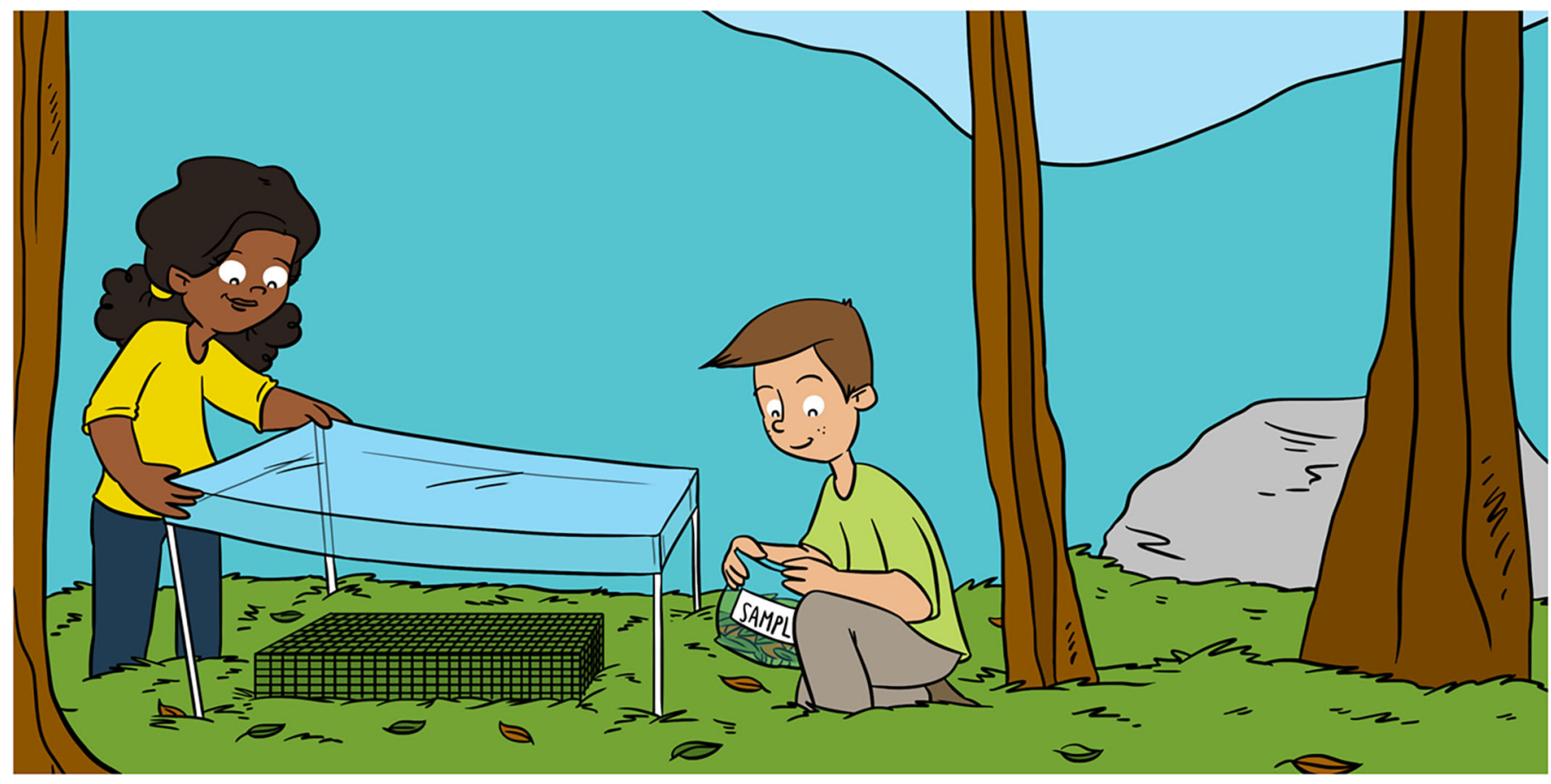

\title{
STUDYING THE ACTIVITY OF LEAF-LITTER FAUNA: A SMALL WORLD TO DISCOVER
}

\section{Dolores Ruiz-Lupión * , María Pilar Gavín-Centol and Jordi Moya-Laraño}

Department of Functional and Evolutionary Ecology, Estación Experimental de Zonas Áridas, Consejo Superior de Investigaciones Científicas (EEZA-CSIC), Almería, Spain

YOUNG REVIEWER:

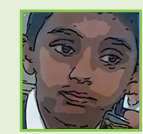

SASYAK

AGE: 12
Hundreds of thousands of little creatures live in soils. Some eat live plants, live animals, or both. Others, called decomposers, consume dead plants, and the waste of other living beings (their feces and their dead bodies), and transform them into food for plants. The health of soils depends largely on the presence of decomposers, and thus it is necessary to study how these creatures may be affected by climate change. To this end, we built a new type of traps to catch live soil animals, which we called cul-de-sac and basket traps. Here, we show how these traps are better for studying animal activity (how much they move in the soil) compared to the most used devices to date, pitfall traps. Comparatively, our traps capture more active animals and prevent predators from killing prey inside, which will improve the accuracy of future studies all over the world. 
SOIL FAUNA

The set of animals that live within or on top of the soil (springtails, mites, spiders, centipedes, earthworms, etc.). This contrasts to soil microbiota (bacteria and fungi) also important for soil functioning.

\section{LEAF-LITTER}

The top soil layer of dead leaves $(1 \mathrm{~cm}-1 \mathrm{~m}$ depth) in terrestrial ecosystems, such as forests and scrublands, which provides habitat and food to a large diversity of organisms.

\section{FOOD WEB}

A natural network of connections (interactions) among organisms that feed on each other.

\section{VIDEO 1}

An illustrative video of a crumbling food web as a "house of cards."

\section{WHY ARE LIVING BEINGS SO IMPORTANT FOR SOILS?}

Soils are largely unknown universes, complex systems formed by a mixture of air, minerals, organic compounds, and living organisms that are related to each other and with the environment. These relationships between living beings are called interactions, which take place when organisms communicate, feed on each other or pollinate flowers, among others. Currently, we do not know how many species of animals, fungi, and bacteria live in the first four meters of soil (Figure 1, soil profile); but we do know that soils contain the greatest biodiversity on Earth, with about 1.5 million described species out of a total of an estimated 2 billion. Among this overwhelming biodiversity, soil fauna perform many important functions necessary for both soil health and human well-being [1]. For example, one of these functions is the decomposition of dead animals and plants, a process in which dead matter is transformed into food from which plants feed on (Figure 1, orange arrows). Without decomposer animals healthy soils would disappear, and both wildlife and humanity would be affected. Moreover, some of these animals act as ecosystem engineers, creating, modifying, and maintaining the soil structure (as ants or earthworms when digging holes). Other soil-living animals are natural enemies of pests, helping farmers to protect their crops. Therefore, a soil with greater abundance and diversity of fauna will provide more benefits and this is why these organisms are good indicators of soil health [2]. Hence, sampling and analyzing these creatures is essential if we are to understand and preserve the soils and the functions they supply.

\section{THE IMPORTANCE OF LEAF-LITTER FOOD WEBS}

About $97 \%$ of the species of soil fauna are invertebrates, animals without an internal skeleton such as nematodes, potworms, earthworms, slugs, or snails. We mostly like to study a type of invertebrates that often live in the leaf-litter layer and that have external skeletons, segmented bodies, and pairs of appendages with joints: the arthropods. These animals can vary widely in size from very tiny to larger than a hand. Soil arthropods are grouped into two size categories: mesofauna $(0.2-2.0 \mathrm{~mm})$ such as mites and springtails, and macrofauna $(>2.0 \mathrm{~mm}$ ) such as spiders, beetles, centipedes, and millipedes (Figure 1, grey boxes). All these animals organize around what we call food webs, in which predator-prey relationship take place governed by the rule that "big fish eats little fish;" that is, larger species prey (kill and feed) on several smaller ones, while small species prey on even smaller species or on the offspring of larger ones (Figure 1, black arrows). This interdependence among species means that food webs are fragile systems, in which the extinction of one species can cause the extinction of others, making the entire food web to crumble as a "house of cards" (Video 1). Therefore, studying the functioning of food webs is crucial for soil health monitoring. 
Figure 1

The leaf-litter food web. The abundance and diversity of soil fauna is critical for soil health. Black arrows show "who eats whom," and organisms can be classified into:

(1) primary

decomposers that directly feed on the leaf-litter; (2) secondary decomposers that feed on primary

decomposers; (3) small predators that feed on primary and secondary decomposers; and (4)

large predators that

feed on small predators and large

decomposers. Orange arrows show the decomposition process, by which dead matter is transformed into food from which plants feed upon. To complete the decomposition process of the falling leaves (brown arrow), sunlight, rainfall and a good airflow are also necessary.

\section{ACTIVITY}

The amount of animal movement per unit of time (minutes,

hours, etc.).

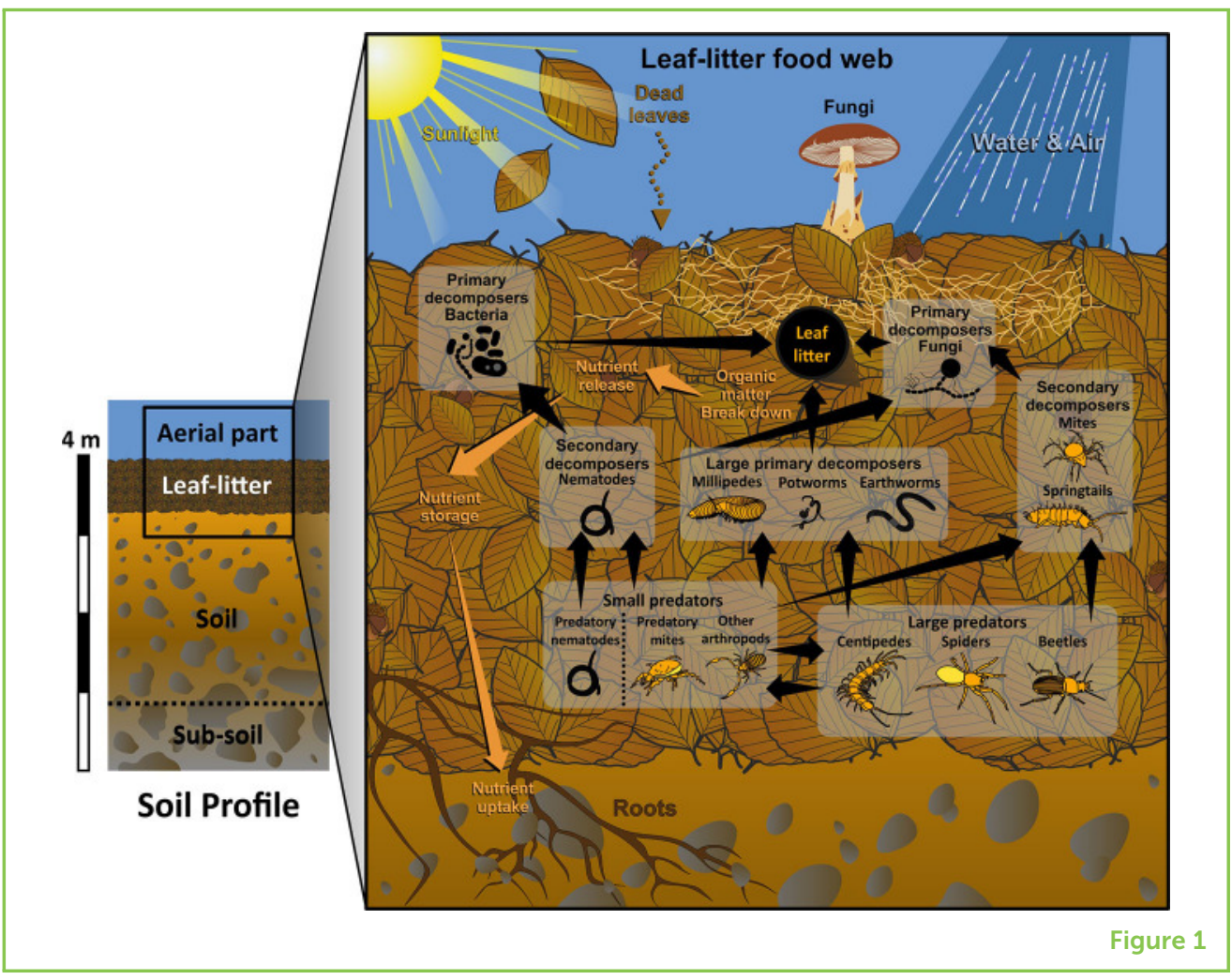

\section{USING TRAPS TO MEASURE THE ACTIVITY OF LEAF-LITTER ARTHROPODS}

Not all soil animals search food at the same time, nor for the same amount of time, which determines which animals encounter and interact with each other in the soil. Therefore, predator-prey interactions in food webs could be influenced by the activity patterns (e.g., diurnal or nocturnal) of different animals. Our main goal is to study the activity of leaf-litter arthropods using different types of traps. The use of traps for measuring animal activity may be an appropriate approach to monitor the functioning and health of soils. Even so, it is still unclear if trap catches are an estimate of activity, abundance, or a mixture of both [3]. This is because traps in a location with more arthropods will catch a larger number of them if they are more abundant, but also if they move around for longer time (that is, because they are more active). Since the early 1900s, the standard method for collecting soil fauna and measuring the abundance and/or diversity of soil arthropods has been the use of pitfall traps. These traps consist of cups buried in the soil in which fauna crawling through the leaf-litter fall. The cups are usually partially filled with a liquid to kill and preserve the trapped organisms. Besides pitfall traps, there are other methods of sampling abundance and/or diversity of soil arthropods [4]. In our study, we were interested in assessing the activity-not just the abundance-of soil arthropods. Therefore, we used pitfall traps without preservative liquid, which allowed collecting live specimens that could be returned to the leaf-litter. 
However, pitfall traps have many problems, including the fact that animals that are too small or too large do not fall into them, either because they are longer than the trap entrance or so small that they detect the edge of the trap and move away from it. Some animals can even walk on the trap walls without falling in. This means that pitfall traps might not give us good estimates of the entire leaf-litter community, which could lead to improper conclusions about predator-prey interactions when using pitfall traps [3]. Thus, we developed two new trapping devices to improve the monitoring of animal activity, small mesh fabric bags in the shape of a sock named "cul-de-sac" traps, and square baskets made of wireframe similar to a box with holes without a lid named "basket" traps [5], in which the transition between the edge of the trap and the surrounding litter is less noticeable to soil animals than in pitfall traps.

\section{DISTINGUISHING ACTIVITY FROM ABUNDANCE}

Our main goal was to find which traps were better at monitoring animal activity, by means of distinguishing abundance (how many animals are there) from activity (how much do they move). We use traps to estimate activity; that is, animals that fall inside a trap while it is placed in the field should reflect how much they move. However, things are not this simple. For instance, the number of animals directly captured in the leaf-litter is an estimate of their abundance; that is, the quantity of animals present regardless of the moment. Hence, differently than activity, abundance is not affected, for instance, by the weather conditions of the day of the experiment in which we capture the animals. And this is when things get tricky: animal abundance affects how many animals are caught in the traps regardless of their activity. Therefore, in order to differentiate activity from abundance, we had to count and classify the arthropods inside the traps (activity) and within the leaf-litter outside the traps (abundance). This distinction is very important because the measure of soil arthropod activity cannot be done without knowing the abundance. Imagine one location in the soil inhabited by 2 individuals of a species (Sp1) of very active beetles that move around a lot, and by 20 beetles of a very abundant but sedentary species (Sp2); i.e., that do move very little. If our traps collected 2 beetles of each species in that location, we would conclude that the activity of both species was similar. However, in reality the 2 individuals of the former species (Sp1) would be caught by their high activity, while the second two (Sp2) would be caught because this species is much more abundant. Just because Sp2 is present in large numbers two are caught in the traps, even though these beetles move much less. An independent measurement of abundance serves the researchers to correct for these differences and have accurate measurements of activity. 


\section{SETTING UP OUR MESOCOSM EXPERIMENT}

In the spring of 2013, we conducted an experiment in 4 beech forests (Fagus sylvatica L.) from the Cantabrian Mountains, Spain (Figure 2A). Beech trees have relatively large leaves that fall in autumn, forming a leaf-litter layer often deeper than $10 \mathrm{~cm}$, which is shelter to large numbers of arthropods [6]. Working in soils with leaf-litter offers a great advantage: animals live and are active in superficial layers of the soil during most of the time, while in the soils of other terrestrial ecosystems the fauna is mostly active in deeper layers, from which it is difficult to trap live animals.

All traps used in the study were handmade. Pitfall traps (Figure 2C, left) consisted of a plastic cup with the base cut and a fabric attached at the bottom to prevent small animals from escaping while allowing water to drain out. This fabric was very fine, with a mesh of about $200 \mu \mathrm{m}$. In addition, to minimize the entry of sunlight as to mimic the dark conditions within the litter, a wooden square cap was placed on top of each pitfall trap in the leaf-litter. Cul-de-sac traps (Figure 2C, center) were made firm by sewing an oval-shaped wire around the mouth trap. The fabric of these bags was the same as that used for the pitfall traps. Basket traps (Figure 2C, right) consisted of $20 \times 20$ $\times 7 \mathrm{~cm}$ wireframe baskets of $1 \times 1 \mathrm{~cm}$ mesh. Once we built all traps, we placed several square shaped metal enclosures buried in the forest leaf-litter, named mesocosms (Figure 2B). We then collected leaf-litter in the surroundings of each mesocosm, removed all fauna from this litter in the laboratory, filled all traps with this litter free of fauna, and finally placed all traps in the field. Cul-de-sac and basket traps were embedded in the litter layer within the mesocosms, and pitfall traps were buried in the mesocosm soil (Figure 2D). In total, 4 mesocosms were placed in each forest, each with 4 pitfalls, 2 cul-de-sac, and 2 basket traps (Figure 2E). To begin our observations with similar moisture conditions in the traps and the surrounding litter, we placed roofs on the mesocosms to block all rainfall 15 days in advance. This procedure provided with uniform moisture conditions within the mesocosms, ensuring that animals were not moving to seek for, or to avoid humidity.

After collecting the samples from the traps and the leaf-litter outside the traps, five steps were then followed in the laboratory: (1) we weighed the leaf-litter of each sample (wet weights); (2) we removed and counted the arthropods; (3) using a dissecting microscope we classified the arthropods according to their size (macrofauna vs. mesofauna), diet (predators vs. prey) and main group (mites, springtails, spiders, centipedes, millipedes, or beetles); (4) we dried the leaf-litter of each trap and weighed it again (dry weights); and (5) we calculated the water content within each trap from the difference between wet and dry leaf-litter weights. We used statistical tools to reach conclusions from the numerical data that we obtained from the field. We needed to use these tools for including a correction 
Figure 2

Our experimental setup. (A) Our study was conducted in 4 beech forests in Asturias, Spain. (B) We set up mesocosms that were partially buried in the soil, each with a fiberglass screen on top to prevent the escape of arthropods and a plastic roof to block rainfall. (C) Each mesocosm contained "pitfall" traps and the new "cul-de-sac" and "basket" traps. (D) Pitfall traps were buried in the soil, whereas

cul-de-sac and basket traps were embedded within the leaf-litter layer. (E) Top-down view of a mesocosm with 4 pitfall, 2 cul-de-sac and 2 basket traps

(photographs and some drawings were reused from the Original Source Article).

A

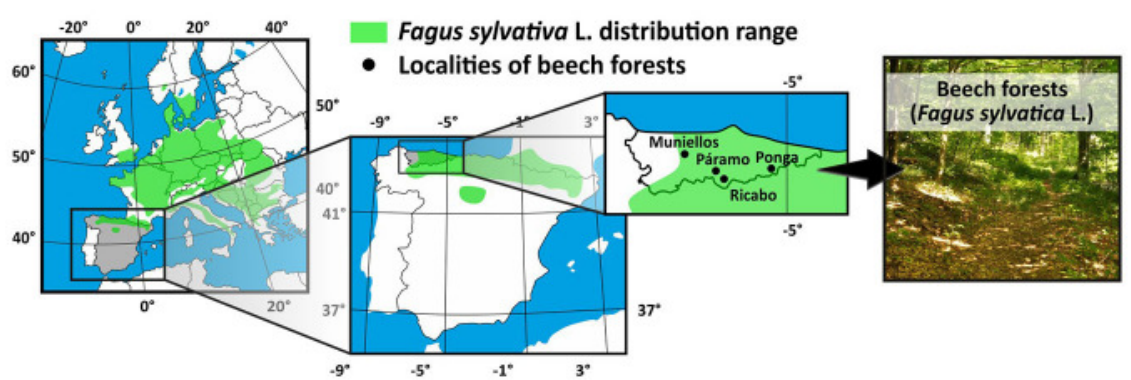

MESOCOSM - Side view

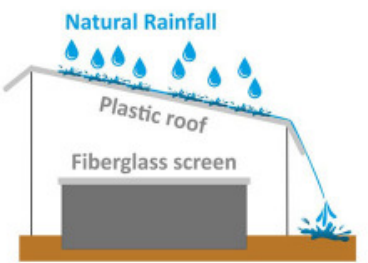

\section{STANDARD TRAP Pitfall trap}

$x 4$

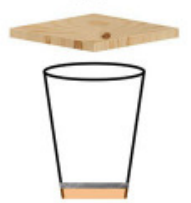

D

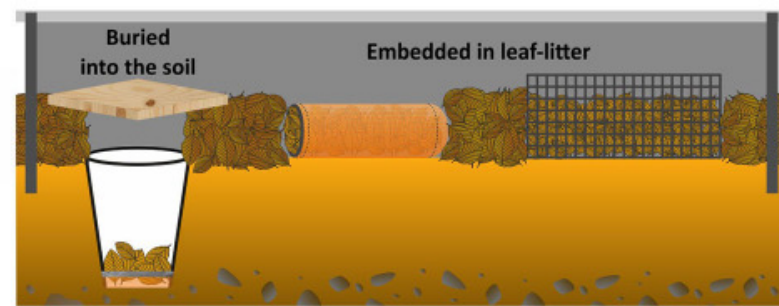

E

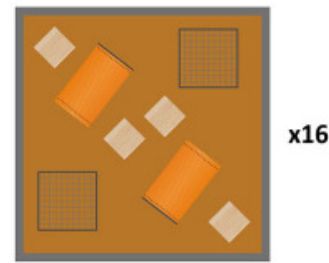

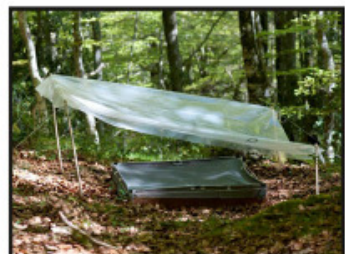

NEW TRAPS Cul-de-sac trap $\mathrm{x} 2$
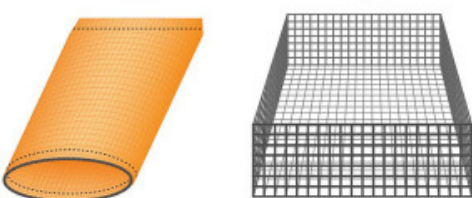

x2
2 cul-de-sac

2 baskets

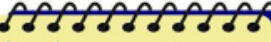

In the experiment:

4 beech farests

$x 4$ mesocosms

16 mesacosms

in total

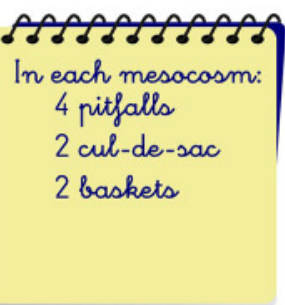

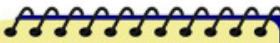

Pitfall traps

Buried

Cul-de-sac traps

Basket traps

Embedded

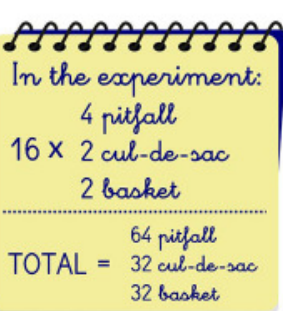

Figure 2

for abundance (see the above section), ensuring that we were testing for differences in activity and not in abundance [7]. In summary, we tested the activity of each group and if some trap types captured some groups more than others. For instance, we compared the catches of large (macrofauna) vs. small (mesofauna) animals, as well as those of predators vs. prey. With this set of comparisons, we could assess what kind of trap works better for studying arthropod activity. 
Figure 3

What type of trap best measures the activity of leaf-litter fauna? To estimate the natural abundance of arthropods, we collected 5 samples of leaf-litter from each mesocosm. We also collected pitfall, cul-de-sac and basket traps to estimate arthropod activity. Compared to the new traps, pitfall traps: (A) retained twice the amount of water as the other two traps; (B) captured $20-33 \%$ the amount of animals per unit of time; for example, per hour, than the new traps; (C) caught more macrofauna than mesofauna; and (D) caught more predators than prey. This told us that the new traps are better measuring the activity of soil arthropods

(photographs and some drawings were reused from the Original Source Article).

\section{WHAT TYPE OF TRAP BEST MEASURES ACTIVITY?}

Through our experiments, we found that cul-de-sac and basket traps performed better than pitfalls trap. First, pitfall traps retained almost twice the amount of water than cul-de-sac and basket traps, which could result in attraction for some animals or repulsion for others. Additionally, the litter in these new traps had similar water content than that in the surrounding litter outside the traps (Figure 3A). Second, cul-de-sac and basket traps caught around 3-5 times more animals per unit time, for example per hour, than pitfall traps. Thus, the latter underestimated the activity of leaf-litter fauna (Figure 3B). Third, pitfall

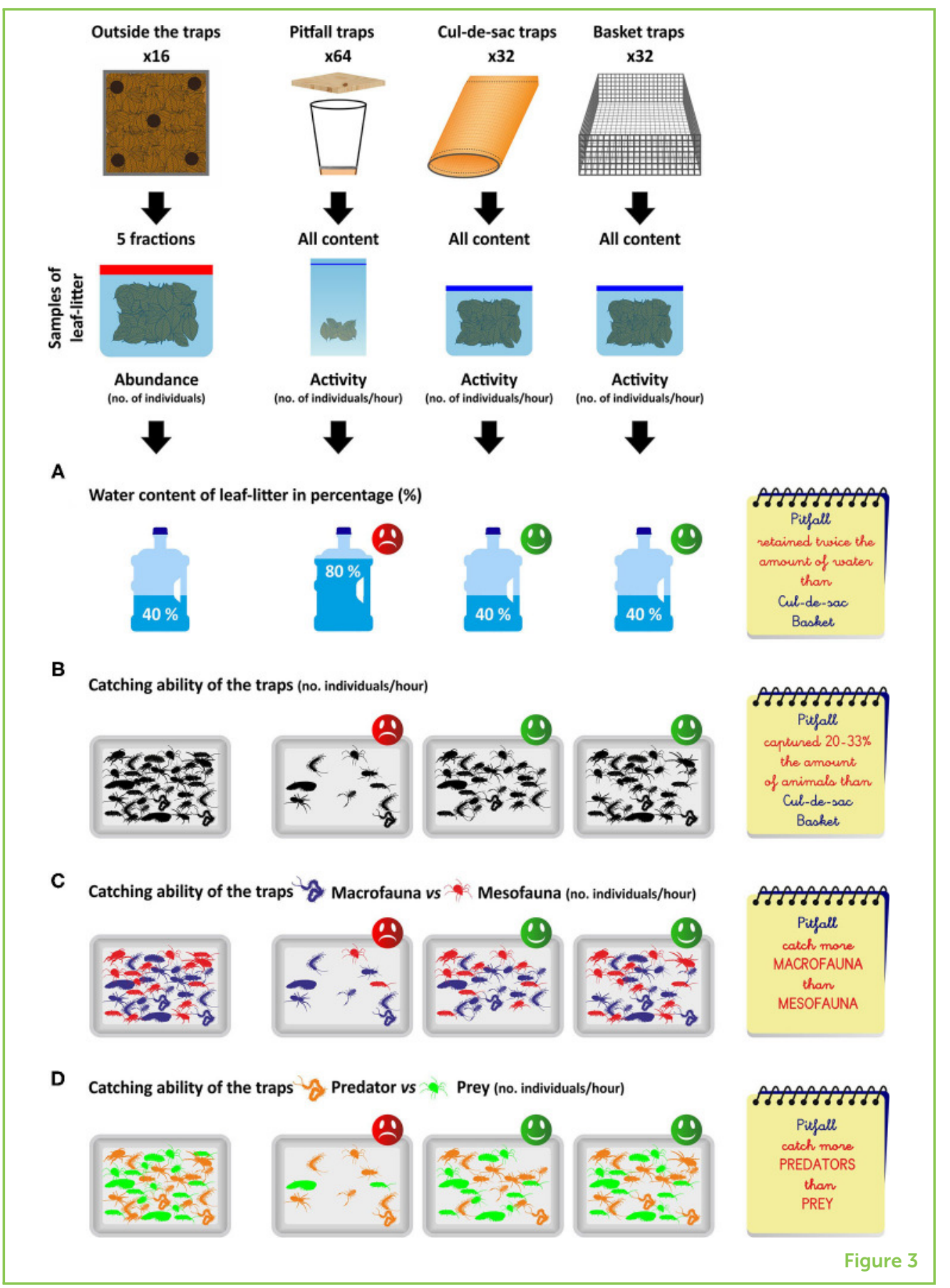


traps captured more macrofauna than mesofauna and more predators than prey. This means that the predators that fell into the pitfall traps could have eaten some of the smaller fauna before we collected the traps (Figures 3C,D). Therefore, we concluded that cul-de-sac and basket traps performed much better than pitfall traps.

\section{WHY DO THESE NEW TRAPS MATTER?}

Our new cul-de-sac and basket traps are promising tools for soil ecologists, since they perform much better than pitfall traps, which have been widely used to assess abundances over the last century. These new traps will help scientists to more accurately estimate the activity of soil arthropods, which will improve our knowledge of terrestrial ecosystems with leaf-litter. Besides these are cheap devices that one can easily build him/herself (with fabric, wires, plastic, and/or metal meshes of different sizes, some glue, and leaf-litter), allowing one to learn more about soil animals and, therefore, about the health of ecosystems. These new traps capture animals more efficiently, minimize the predation on small ones and do not attract/repel animals because of differences in moisture between trap and the surrounding leaf-litter. In addition, these traps can not only be used in soils with a deep leaf-litter layer (like forests or jungles), but also in any ecosystem that has a well-defined leaf-litter layer, such as under shrubs in scrubs and savannas. This work is also very important because we need to understand how climate change may negatively affect food webs (feeding interactions among species) and the important functions and benefits that soil ecosystems provide. We are already working on it, through tools like these new traps and field experiments in which we modify rain or predators. Thus, we should not miss this opportunity and get to know the wonderful but hidden soil fauna. Because it is everyone's heritage and because it protects us all, now more than ever we have to study and preserve the soils and the life they host.

\section{ACKNOWLEDGMENTS}

We thank J. Pascual, N. Melguizo-Ruiz, and O. Verdeny-Vilalta, co-authors of the original scientific article; E. de Mas, J. Pato, and G. Jiménez, who helped with field sampling; and E. de Mas for photographs. We also thank the Research Unit of Biodiversity (UMIB, $\mathrm{UO} / \mathrm{CSIC/PA}$ ) at Mieres (Asturias) for logistical support. This work was done under Asturias Government permit 2011/059163 and funded by grants CGL2010-18602 and CGL2015-66192-R from the Spanish Ministerio de Economía y Competitividad (European funds FEDER), 020/2008 from Spanish Organismo Autónomo de Parques Nacionales, and P12-RNM-1521 from Junta de Andalucía (European funds FEDER). DR-L enjoyed a FPU (FPU13/04933) scholarship from the Spanish Ministerio de Educacion, Cultura y Deporte. 


\section{ORIGINAL SOURCE ARTICLE}

Ruiz-Lupión, D., Pascual, J., Melguizo-Ruiz, N., Verdeny-Vilalta, O., and Moya-Laraño, J. 2019. New litter trap devices outperform pitfall traps for studying arthropod activity. Insects. 10:147. doi: 10.3390/insects100 50147

\section{REFERENCES}

1. Briones, M. J. I. 2018. The serendipitous value of soil fauna in ecosystem functioning: the unexplained explained. Front. Environ. Sci. 6:149. doi: 10.33 89/fenvs.2018.00149

2. Brackin, R., Schmidt, S., Walter, D., Bhuiyan, S., Buckley, S., and Anderson, J. 2017. Soil biological health - what is it and how can we improve it? Proc. Aust. Soc. Sugar Cane Technol. 39:141-54.

3. Lang, A. 2000. The pitfalls of pitfalls: a comparison of pitfall trap catches and absolute density estimates of epigeal invertebrate predators in Arable Land. J. Pest Sci. 73:99-106. doi: 10.1007/BF02956438

4. McCravy, K. W. 2018. A review of sampling and monitoring methods for beneficial arthropods in agroecosystems. Insects 9:170. doi: 10.3390/insects 9040170

5. Ruiz-Lupión, D., Pascual, J., Melguizo-Ruiz, N., Verdeny-Vilalta, O., and Moya-Laraño, J. 2019. New litter trap devices outperform pitfall traps for studying arthropod activity. Insects 10:147. doi: 10.3390/insects10050147

6. Melguizo-Ruiz, N., Jiménez-Navarro, G., De Mas, E., Pato, J., Scheu, S., Austin, A. T., et al. 2020. Field exclusion of large soil predators impacts lower trophic levels and decreases leaf-litter decomposition in dry forests. J. Anim. Ecol. 89:334-46. doi: 10.1111/1365-2656.13101

7. Shultz, B. J., Lensing, J. R., and Wise, D. H. 2006. Effects of altered precipitation and wolf spiders on the density and activity of forest-floor Collembola. Pedobiologia 50:43-50. doi: 10.1016/j.pedobi.2005.10.001

SUBMITTED: 16 April 2020; ACCEPTED: 06 September 2021; PUBLISHED ONLINE: 08 October 2021.

EDITED BY: Helen Phillips, Saint Mary's University, Canada

CITATION: Ruiz-Lupión D, Gavín-Centol MP and Moya-Laraño J (2021) Studying the Activity of Leaf-Litter Fauna: A Small World to Discover. Front. Young Minds 9:552700. doi: 10.3389/frym.2021.552700

CONFLICT OF INTEREST: The authors declare that the research was conducted in the absence of any commercial or financial relationships that could be construed as a potential conflict of interest.

COPYRIGHT @ 2021 Ruiz-Lupión, Gavín-Centol and Moya-Laraño. This is an open-access article distributed under the terms of the Creative Commons Attribution License (CC BY). The use, distribution or reproduction in other forums is permitted, provided the original author(s) and the copyright owner(s) are credited 


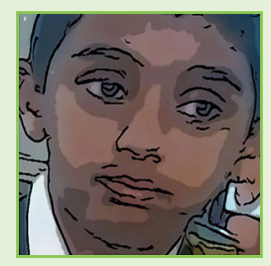

and that the original publication in this journal is cited, in accordance with accepted academic practice. No use, distribution or reproduction is permitted which does not comply with these terms.

\section{YOUNG REVIEWER}

\section{SASYAK, AGE: 12}

Sasyak is a 12-year old student from India. He is an avid reader of several genres of books. He is a keen participant in quiz contests and olympiads, and is a spell bee champion. He attends football classes and enjoys cycling.

\section{AUTHORS}

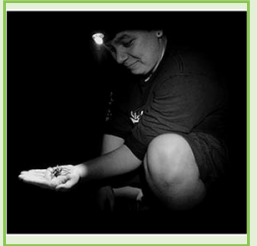

\section{DOLORES RUIZ-LUPIÓN}

I started my academic career with two bachelor degrees one in Marine Sciences and another in Environmental Sciences, and later I received a Master degree in Evaluation of Global Change. Afterwards, I completed my PhD in Evolutionary Ecology at the Estación Experimental de Zonas Áridas, Consejo Superior de Investigaciones Cientificas (EEZA-CSIC). My scientific interest is the study of terrestrial and aquatic food webs through field and laboratory experiments, as well as theoretical approaches using mathematical models and computer simulations. I am very enthusiastic about scientific illustration and I design figures for other researchers. *loli.ruiz@eeza.csic.es; loli.ruizlupion@gmail.com ${ }^{\dagger}$ Dolores Ruiz-Lupión, Laboratory of Arid Zones and Global Change, Department of Ecology, Instituto Multidisciplinar para el Estudio del Medio "Ramón Margalef" (IMEM), Universidad de Alicante (UA), Spain

\section{MARÍA PILAR GAVÍN-CENTOL}

I am a pre-doctoral student at the Estación Experimental de Zonas Áridas, Consejo Superior de Investigaciones Científicas (EEZA-CSIC). Since I was a child, animals have always amazed me, but even more since I learned that nematodes (tiny worm-shaped animals) can "wake up" after spending about 40,000 years on ice! That is why, after my studies in Biology, a master's degree and two internships, I began to investigate the mechanisms by which these and other soil animals are affected by increased droughts and how their drought-driven inactivity affects ecosystem functioning, both in natural and human-modified ecosystems.

\section{JORDI MOYA-LARAÑO}

I have been live-collecting and observing bugs in nature since I was a child. I am passionate about wilderness and I consider myself a naturalist. As a consequence I also adore my job as an evolutionary ecologist. In our group, we conduct both field and laboratory experiments to understand the role of water in soil food webs. We also perform computer simulations that recreate both ecology and evolution in food webs, and my dream is to achieve realistic simulation scenarios that match our field experiments. 